\title{
Effect of Glomus microcarpum in Relation to the Biomass Production of Wheat Plants
}

\author{
Nirmala Dhungana ${ }^{1}$, Prakash Raut ${ }^{2}$ and Anjana Singh ${ }^{1}$ \\ ${ }^{1}$ Central Department of Microbiology, Tribhuvan University, Kirtipur, Kathmandu \\ ${ }^{2}$ Nepal Academy of Science and Technology, Khumaltar, Lalitpur \\ e-mail: dhungananiru@yahoo.com
}

\begin{abstract}
Many studies have shown that mycorrhizal inoculations enhance the growth and nutrient uptake by plants. However, in Nepal, the focus of study is being given to the leguminous plants. To study the effect of vesicular-arbuscular mycorrhiza (VAM) in the biomass production of wheat, common VAM fungus Glomus microcarpum was inoculated in four varieties of wheat (Triticum aestivum) (i.e. WK 810, WK 1320, WK 1357 and WK 2089); the VAM spores being isolated by wet sieving and decanting process. Recording effects were started after one week of seed sowing, then weekly for growth parameters and on 15 days interval for edaphic parameters. In all cultivars, increased root and shoot biomass were recorded in inoculated ones compared to their non-inoculated counterparts. The reaction to the $G$. microcarpum inoculants was not different significantly for all cultivars when comparison was made on them on $89^{\text {th }}$ day after inoculation, where the biomass values were recorded maximum. Also, phosphorus and organic matter contents of soil related inversely to the VAM fungal spore number in the soil and the root infection. This study demonstrates the potential use of G. microcarpum as biofertilizer in nutrient poor soils.
\end{abstract}

Key words: vesicular-arbuscular mycorrhizae, Glomus microcarpum, Triticum aestivum

\section{Introduction}

The vesicular-arbuscular mycorrhizae (VAM) are most commonly reported groups since they occur on a vast taxonomic range of plants, both herbaceous and woody plants (Singh 2004). Roughly $90 \%$ of world plant species belonging to various families are thought to form symbiotic mycorrhizal association (Malajezuk et al. 1992). Mycorrhizal symbionts increase the efficiency of nutrient acquisition by plants and hence soil fertility (Sharma 2001). These fungi build a living bridge between plant root and bulk soil in most ecosystems (Singh 2004, Sharma 2001).VAM are formed by non-septate fungi. These fungi are obligate symbionts resulting from mutual symbiosis and have not been cultured on nutrient media. They cannot be grown in isolation in pure culture. The mycorrhiza-plant relationship is particularly important for agricultural plants that have large requirements for nutrients and water, basically phosphorus, to achieve optimum yield. These fungi excrete powerful chemicals that dissolve mineral nutrients, absorb water, retard soil pathogens, and glue soil particles together into porous structure. In return, they receive sugars and other compounds from plants to fuel their activities. Research has documented improved plant nutrition and water uptake and resistance to a wide range of environmental extremes. Plants establish and yield more abundantly and require less intensive care. This is one among the major reasons why plants from natural undisturbed areas can thrive without irrigation, fertilizer and pesticides. A major benefit conferred by VAM fungi on their host plants is stimulation of growth from the improved phosphate uptake by inoculated plant roots (Douds et al. 2000). Extraradical hyphae of mycorrhizae greatly enlarge the accessible soil volume for phosphorus acquisition (Li et al. 1991). In addition, phosphorus taken up is efficiently transported to plant roots (Smith \& Smith 1990).

Despite the vast data available on microbiological aspects and their role, there has been no extensive research on VAM fungi and their effect in productivity of the crop plants. However, many fertilizers, are being used in the agricultural field for improved production in our country. Keeping in mind the significance of mycorrhizae in the productivity of crops, this present investigation was carried out to observe role the of $G$. microcarpum in the productivity of wheat plant (Triticum aestivum. Among the various VAM fungi, this species was selected because of its higher rate of infection and more potentials in terms of productive value.

\section{Methodology}

The present study was carried out from January to April, 2006. Pot experiments were established in the 
garden of Nepal Academy of Science and Technology, Khumaltar, Lalitpur. G. microcarpum, a VAM fungus, was employed as root symbiont to develop a symbiotic system with the roots of wheat. Four varieties of wheat namely, WK 810, WK 1320, WK 1357 and WK 2089 were selected for this study.

For the collection of VAM fungal spores, soil samples were collected from the rhizosphere zone of various plants from the depth of $5-7 \mathrm{~cm}$ from Godawari, Phulchoki and Chandragiri forest areas. VAM fungal spores were extracted from the soil by subjecting the soil samples to wet sieving and decanting (Gerdeman $\&$ Nicolson 1963). The spores were observed under stereoscopic binocular and identified according to original species description (Gerdeman \& Trappe 1974, Hall \& Fish 1979). The spores were picked up with the help of a sharp needle and collected in sterile distilled water.

The soil (red colored) for the experiment was procured from Godawari and sterilized by autoclaving at $121^{\circ} \mathrm{C}$ for 2 hours for three consecutive days. Earthen pots $(23 \mathrm{~cm}$ diameter) were sterilized with $70 \%(\mathrm{v} / \mathrm{v})$ ethanol and filled with $5 \mathrm{~kg}$ of the soil (clay loam- $30.7 \%$ sand, $41.4 \%$ silt, $27.9 \%$ clay, organic matter $0.776 \%$, $\mathrm{pH} 7.6$, nitrogen $0.084 \%$, phosphorus $25.6 \mathrm{~kg} / \mathrm{ha}$, potassium $67.2 \%$ ). The following treatments were imposed in a completely randomized design with five replications for each set of pot with soil: 1. plants inoculated with G. microcarpum, and 2. control plants without inoculation, for all four wheat varieties. Wheat seeds (25 seeds per pot) were sown in each pot. Inoculations with the fungal spores were done before

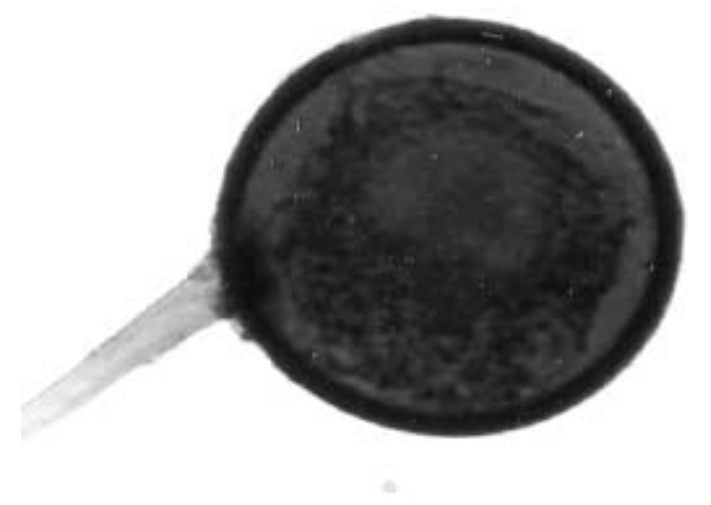

Fig. 1. Spore of G. microcarpum seed sowing (25 spores per pot). The plants were allowed to grow for 92 days of seed sowing. During the experiment, root and shoot fresh weight, root and shoot dry weight (dried in hot air oven at $80^{\circ} \mathrm{C}$ ), \% mycorrhizal colonization and spore number in rhizospheric soil were determined weekly after 15 days of seed sowing. For assessment of root colonization, roots were washed with $10 \% \mathrm{KOH}$ followed by staining with $0.05 \%$ trypan blue in lactophenol (Phillips \& Hayman 1970). The root pieces $(1 \mathrm{~cm})$ were selected at random from the stained samples and mounted on a microscopic slide in groups of 10. Presence of infection was recorded in each of the 10-pieces and was calculated according to Singh (2004):

Percent colonization $=\frac{\text { Number of colonized root segments }}{\text { Total number of segments examined }} \times 100$

In all, 50 root segments were examined. For estimation of the spores of G. microcarpum in the same soil samples used for root colonization, spores were isolated by wet sieving and decanting method (Gerdeman \& Nicolson 1963). Number of spores per $20 \mathrm{~g}$ soil was calculated. Organic matter, $\mathrm{pH}$, total nitrogen, free phosphorus and free potassium content of soil were determined at 15 days interval of seed sowing.

\section{Results and Discussion}

The soil was collected from rhizospheric areas of different plants of dry and undisturbed land for collection of spores (Fig. a) for inoculum as the mycorrhizal efficiency is more pronounced in such condition. Disturbance of land significantly reduces the inoculum potential of the soil i.e. propagules and/or stability of hyphal network (Reeves et al. 1979).

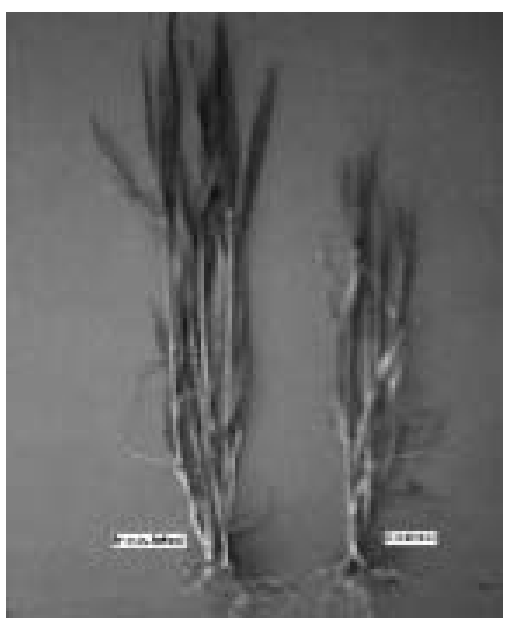

Fig. 2. Effect of G. microcarpum inoculants on wheat (WK 1357) on $82^{\text {nd }}$ day after plantation 


\section{N. Dhungana et al./Effect of Glomus microcarpum in Relation}

The native VA mycorrhizal population was less in black soil (vertisol) as compared to red soil (Hiremath et al. 1990). The black soils with sandy loam texture exhibited higher mycorrhizal activity than those with clay texture. The clay content in soil was also found to influence the VA mycorrhizal population. Owing to this, red colored soil (alfisol) was collected for our experiment.

G. microcarpum inoculations increased root biomass on all the days observed. Higher fresh and dry weight was found in inoculated plants in comparison to control plants. The weights of fresh and dry roots of inoculated plants were higher which might be due to the high number of lateral roots and root hairs, which eventually increased the root dry weight. Readings on all the days were higher in inoculated plants than in noninoculated ones. Similar result has been shown by Hetrick et al. (1985) that in well infected root, mycorrhiza constitutes about $10 \%$ increment of root biomass.

G. microcarpum inoculation increased the shoot biomass yield over control on all the days observed in this experiment. The increased shoot biomass production by the inoculated plants could be attributed to enhanced inorganic nutrient absorption and greater rates of photosynthesis in inoculated plants. Similar result has been shown by Cooper (1985). It seems likely that in this study inoculation increased nutrient uptake by shortening the distance that the nutrients had to diffuse from the soil to the roots giving rises to a higher root and shoot biomass increment with a uniform growth. Many authors have reported a significant

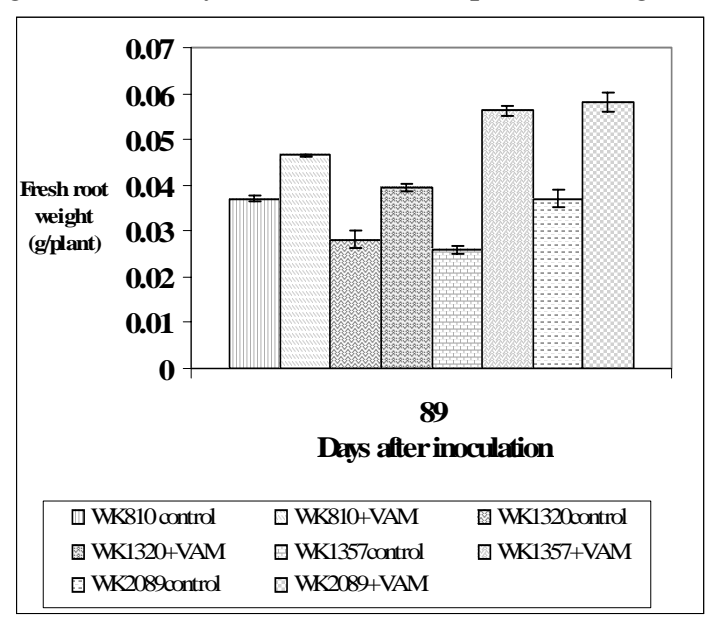

Fig. 3. Effect of VAM inoculation on fresh root weight of four varieties of wheat at $89^{\text {th }}$ day after inoculation increment in shoot biomass, after inoculating the plants with mycorrhiza. Kung (2006) has demonstrated that there is significant increase in root and shoot biomass in VAM inoculated plants than in control plants. An increase in nutrient uptake, especially phosphorus in the infertile soil used, could have resulted in relief of nutrients stress and an increase in photosynthetic rate, which obviously could have given rise to an increase in plant growth. As reported by Klironomos et al. (2000), the combinations of plants and VAM fungi results in a more efficient extraction of nutrient from soil.

The maximum growth of the plants (root and shoot biomass for all cultivars) was observed on the $89^{\text {th }}$ day after inoculation of G. microcarpum. After this the biomass decreased due to aging and drying up of the plants. So, comparison was made for this period among different wheat cultivars to find out better productive variety with inoculation of $G$. microcarpum in pot culture experiment. None of the wheat varieties could be most effective as they were all more or less similar in their root and shoot biomass, the difference was not significant $(\mathrm{P}<0.05)$, whereas the difference between the inoculated with their noninoculated counterparts was significant (Fig b, Fig. 1, 2, 3, 4). However, G. microcarpum showed better influence in terms of fresh root weight in WK 2089, dry root weight, fresh shoot weight and percent colonization in WK 1357, and in dry shoot weight in WK 810 in comparison to other cultivars.

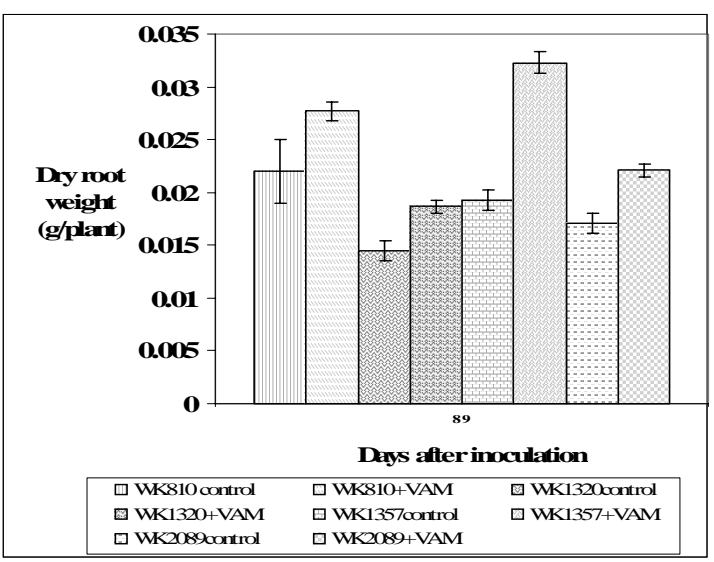

Fig. 4. Effect of VAM inoculation on dry root weight of four varieties of wheat at $89^{\text {th }}$ day after inoculation 


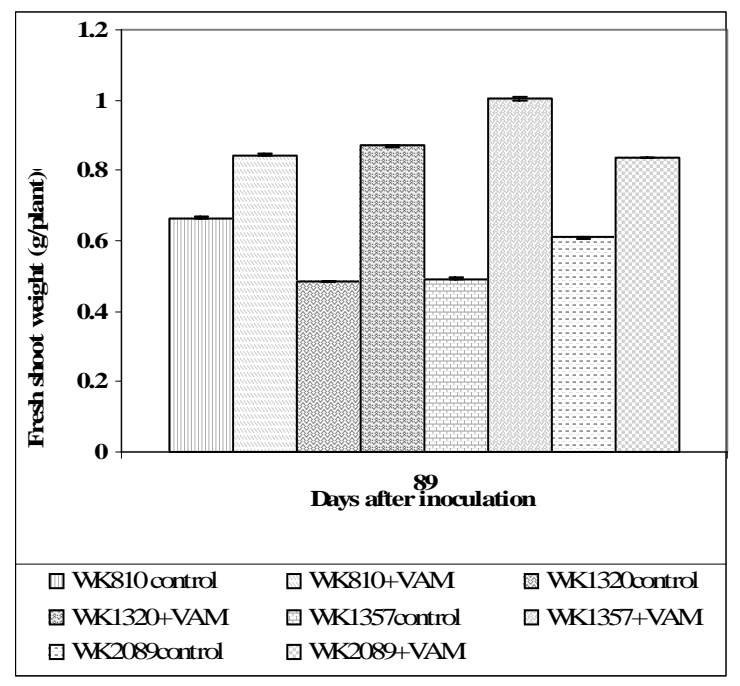

Fig. 5. Effect of VAM inoculation on fresh shoot weight of four varieties of wheat at $89^{\text {th }}$ day after inoculation

Many studies have shown that there is a lag phase between mycorrhiza inoculation and the time period when its effect is manifested in the plant (Brandon \& Shelton 1993). Similar result has been observed in the present investigation also. This may be the reason that the inoculated plants in our experiment showed better results later on than those of only a few days after inoculation. The experiment was conducted free of contamination of any harmful creatures or chemicals as there was no marked change in $\mathrm{pH}$. Also the plant growth was normal i.e. the root and shoot biomass was in increasing trend except in the last day of observation. The decrease in biomass on the last observation is due to ageing of plants as the consequence of death and fall of leaves and death of old roots.

In this investigation, the increment in percentage colonization of mycorrhiza with time was observed. This could have been because of the reason that the root system infected normally increases with time sigmoidally (Kung 2006). Negligible root colonization with VAM fungi during January (only up to $8 \%$ among the cultivars) sampling was observed when the plants were at the 4-to 5-leaf stage in all plots. Once established, the level of root colonization with VAM fungi increased with time, peaking at the heading stage in all plots. Very low levels (2-4\% colonization) of VAM fungi in plant roots sampled at the 4-to 5-leaf stage suggests that the infection rate of wheat plants with these

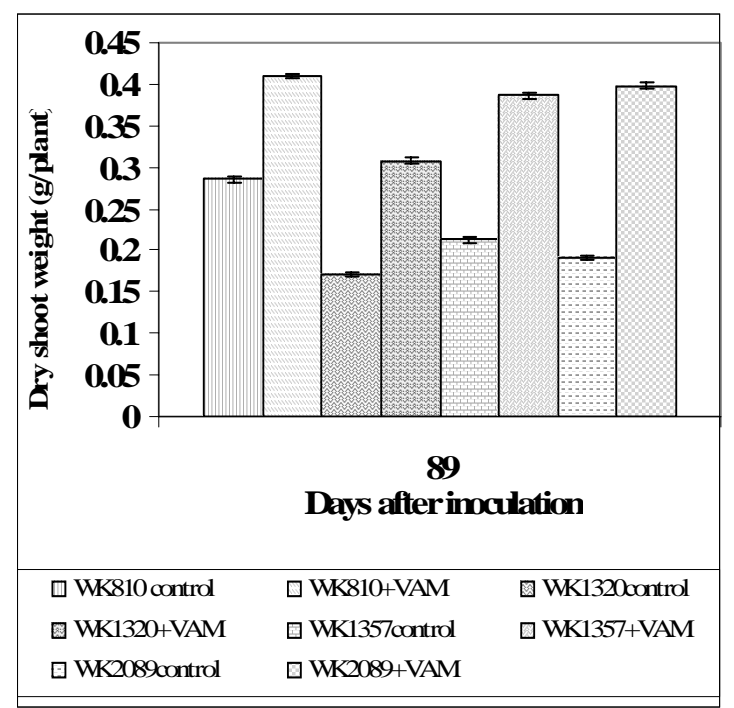

Fig. 6. Effect of VAM inoculation on dry shoot weight of four varieties of wheat at $89^{\text {th }}$ day after inoculation

fungi was either intrinsically slow or that suboptimal (e.g., low temperature) soil conditions slowed colonization. Similar results have been found by Mohammad et al (1998). The highest level of colonization by AM fungal inoculation was attained at heading stage of all cultivars (76\% for WK 810 and WK1320, 78\% for WK 1357, and 74\% for WK 2089). The level of colonization declined (up to $70 \%$ ) during the grain-filling stage. Similar results were reported by Cade-Menun et al. (1991), who suggested that as grains ripen, photosynthesis slows down and nutrients are translocated from the leaves to the grains, which reduce the photosynthate supply to roots and results in a decline in colonization observed during grain-filling.

In this investigation, the spore number in the rhizospheric soil of the inoculated plants was affected by the phosphorus and organic matter content and viceversa. Before inoculation as well as in control plants no spore could be observed, whereas in inoculated ones, 4-8 spores (per $20 \mathrm{~g}$ of soil) were found among the cultivars during first reading peaking the values to 52 for WK 810, WK 1320 and WK 2089, and 60 for WK 1357, where the colonization percentage was also found highest. The free available phosphorus increased, in consequence the spore numbers decreased or remained steady. Phosphorus levels during first reading after inoculation were 133.4, 68.8, 164.2, and 141.1 for WK 810, WK 1320, WK 1357 and WK 2089 respectively. 
But while taking last reading, values for respective varieties were found to be $25.65,10.3$, 87.2, and 35.9. Similar effect was observed in case of organic matter content also. When the spore numbers were highest, the value of organic matter was 0.676 for WK $810,0.672$ for WK $1320,0.776$ for WK 1357, and 0.724 for WK 2089; the figures were $0.853,0.724,1.008$ and 1.241 respectively when the spore numbers were very low. Earlier research conducted by Raut (1994) has also observed similar results, where VAM fungal spore number was inversely correlated with the organic matter content and phosphorus status. As per the results obtained, hardly any prediction could be made for the $\mathrm{pH}$, potassium and nitrogen content status and their relation with the VAM fungi; they were not found to show any marked effect that may be due to short period of time to show the effect. However, Raut \& Mukerjee (2001) have shown that when acidic level increases, VAM fungi decrease.

On the basis of results of this research, $G$. microcarpum would be an effective biofertilizer if inoculated in WK 1357 cultivar for better production and yield in future.

\section{References}

Brandon, N.J. and H.M. Shelton. 1993. Role of vesiculararbuscular mycorrhizae in Leucaena establishment. Proceedings of the XVII International Grassland congress (February 18-21,1993), Australia. New Zealand Grassland Association, New Zealand. pp. 2064-2065.

Cade-Menun, B.J., S.M. Berch, and A.A. Bomke. 1991. Seasonal colonization of winter wheat in South Coastal British Columbia by VAM fungi. Canadian Journal of Botany 69: 78-86.

Cooper, K.M. 1985. Physiology of mycorrhizal associations. In: VA mycorrhiza (Eds C.L. Powell \& D. J. Bagyaraj). CRS Press. pp. 205-222.

Douds, D.D., V. Gadkar, and A. Adholeya. 2000. Mass production of VAM fungus biofertilizer. In: Proceedings: Mycorrhizal Biology (Eds K.G. Mukerji \& B.P. Chamola). pp. 197-215.

Gerdemann, J.W. and T.H. Nicoloson. 1963. Spores of mycorrhizal Endogone species extracted from soil by wet sieving and decanting. Transactions of the British Mycological Society 54: 53-63.

Gerdemann, J.W. and J.M. Trappe. 1974. The Endogonaceae in the pacific North West. Mycologia Memoir 5: 1-76.

Hall, I.R. and B.J. Fish. 1979. A key to Endogonaceae. Transactions of the British Mycological Society 73: 261-280.
Hetrick BA, J. Bloom and S.M. Feyerheim. 1985. Root colonization pattern of Glomus epigaeum in nine host species. Mycologia 77: 825-828

Hiremath, P.C., K.M. Harini Kumar, and C.V. Patil. 1990. Density of VA-mycorrhiza lfungi in different crops grown under black soil. In: Current trends in mycorrhizal research (B.L. Jalali \& H. Chand). pp. 20-21.

Kilronomos, J.N. and W.B. Kendrick. 1993. Research on mycorrhizas: trends in the past 40 years as expressed in the "MYCOLIT" database. New Phytologist 125: 595-600.

Kung, J.B. 2006. Effect of Vesicular-arbuscular mycorrhiza inoculation on growth performance of Senna spectabilis. New Phytologist 133(1):87-94.

Li, X-L., E. George, and H. Marschner. 1991. Extension of the phosphorus depletion zone in VA-mycorrhizal white clover in calcareous soil. Plant and Soil 136: 41-48.

Malajezuk, N., N. Jones, and C. Neely. 1992. The imperative of mycorrhiza to forest trees. The world Bank Asia Technical Department, Agriculture Division. pp. $1-10$.

Mohammad, M.J., W.L. Pan, and A.C. Kennedy. 1998. Seasonal mycorrhizal colonization of winter wheat and its effect on wheat growth under dryland field conditions. Mycorrhiza 8:139-144.

Phillips, J.M. and D.S. Hayman. 1970. Improved procedures for clearing roots and staining parasitic and vesicular arbusclar mycorrhizal fungi for rapid assessment of infection. Transactions of the British Mycological Society 55: 158-160.

Raut, P. 1994. Effect of air pollutants on VA mycorrhiza formation and growth in Leuciaena leucocephla and Prosopis juliflora. Ph. D. dissertation. University of Delhi, India.

Raut, P. and K.G. Mukerjee. 2001. Effect of flyash on diversity and population of VAM fungal spores in the Rhizosphere of Leuciaena leucocephla and Prosopis juliflora. Ecoprint 8(1): 59-63.

Reeves, F.B., D. Wagner, T. Moor-man, and J. Kiel. 1979. The role of endomycorrhizae in revegetation practices in the semi-arid west. I. A comparison of incidence of mycorrhizae mycorrhizae in severely disturbed vs. natural environments. American Journal of Botany 66: 6-13.

Sharma, A.K. 2001. A handbook of organic farming. Agrobios, Jodhpur, India. pp. 216-295.

Singh, A. 2004. Immuno-characterization of Piriformospora indica and Other Identical Root Endophytes. Ph.D. dissertation. Jawaharlal Nehru University, New Delhi, India.

Smith, S.E. and F.A. Smith. 1990. Movement across membranes. In: Mycorrhizae: Physiology and Genetics (Eds V. Gianinazzi-Pearson and S Gianinazzi). Inst Natlde Recherche Agron Paris. pp. 75-84. 
Nepal Journal of Science and Technology 9 (2008) 